\title{
Recurrence of Medically Certified Sickness Absence According to Diagnosis: A Sickness Absence Register Study
}

\author{
C. A. M. Roelen • P. C. Koopmans • \\ J. R. Anema • A. J. van der Beek
}

Published online: 7 January 2010

(c) The Author(s) 2010. This article is published with open access at Springerlink.com

\begin{abstract}
Introduction Sickness absence is a major public health problem. Research on sickness absence focuses on interventions aimed at expediting return to work. However, we need to know more about sustaining employees at work after return to work. Therefore, this study investigated the recurrence of sickness absence according to diagnosis. Methods We analyzed the registered sickness absence data of 137,172 employees working for the Dutch Post and Telecom. Episodes of sickness absence were medically certified, according to the ICD-10 classification of diseases, by an occupational physician. The incidence density (ID) and recurrence density (RD) of medically certified absences were calculated per 1,000 person-years in each ICD-10 category. Results Sickness absence due to musculoskeletal
\end{abstract}

C. A. M. Roelen · J. R. Anema - A. J. van der Beek Department of Public and Occupational Health, EMGO+ Institute for Health and Care Research, VU University Medical Center, Van der Boechorststraat 7, 1081 BT Amsterdam, The Netherlands

C. A. M. Roelen ( $\square)$

ArboNed Corporate Accounts, PO Box 158,

8000 AD Zwolle, The Netherlands

e-mail: corne.roelen@arboned.nl

P. C. Koopmans

ArboNed Statistics, PO Box 141, 9700 AC Groningen,

The Netherlands

J. R. Anema - A. J. van der Beek

Body@Work, Research Center Physical Activity, Work and Health, TNO-VU/VUmc, Van der Boechorststraat 7, 1081 BT Amsterdam, The Netherlands

J. R. Anema - A. J. van der Beek

Research Center for Insurance Medicine AMC-UWV-VU

University Medical Center, Van der Boechorststraat 7,

1081 BT Amsterdam, The Netherlands disorders had the highest recurrence $(\mathrm{RD}=118.7$ per 1,000 person-years), followed by recurrence of sickness absence due to mental disorders $(\mathrm{RD}=80.4$ per 1,000 person-years). The median time to recurrent sickness absence due to musculoskeletal disorders was 409 days after the index episode. Recurrences of sickness absence due to musculoskeletal disorders accounted for $37 \%$ of the total number of recurrent sickness absence days. For recurrences of sickness absence due to mental disorders this was 328 days and $21 \%$, respectively. Unskilled employees with a short duration $(<5$ years) of employment had a higher risk of recurrent sickness absence. Conclusions Interventions to expedite return to work of employees sick-listed due to musculoskeletal or mental disorders should also aim at reducing recurrence of sickness absence in order to sustain employees at work.

Keywords Absenteeism - Sickness absence · Epidemiology $\cdot$ Recurrence of sickness absence

\section{Introduction}

Sickness absence is a major problem, because of the loss of economic productivity, the social insurance costs, and the direct medical costs of long-term disability. In the past, sickness absence was considered to be a socioeconomic and political matter, rather than a medical or public health problem [1, 2]. However, opinions changed after it was reported that men and women with more than 15 days of sickness absence per year are at increased risk of early retirement on medical grounds and have a higher risk of mortality [3-6]. Findings from the British Whitehall II cohort and the French GAZEL cohort showed increased mortality rates among employees who reported sick due to 
common disorders, such as mental disorders, respiratory diseases and circulatory diseases [7, 8]. Therefore, sickness absence is now considered to be a major public health problem, and research on sickness absence has been given priority in European countries [9, 10].

Most research on sickness absence has concentrated on the transition of long-term diagnosis-specific sickness absence towards disability pension [11-14]. In many European countries, long-term episodes of sickness absence ultimately result in a disability pension [15]. Since 2004, disability benefits in The Netherlands are granted after 2 years of sickness absence, regardless of the workrelatedness of the impairments. Thus, a disability pension encompasses both work-related injuries and non workrelated ill health retirement. Therefore, the societal costs of work disability are high, and expediting return to work is an important goal for interventions.

Although return to work is generally considered to be directly related to recovery, the situation is usually more complex, because varying levels of symptom severity are loosely associated with patterns of sickness absence and work disability. Return to work is conceptualized as a dynamic process that not only involves an off-work phase and a work re-entry phase, but also includes the maintenance phase of sustainability of work performance. If phase-specific goals are not achieved, then there is a risk of a relapse to the off-work phase [16]. It should be noted that this dynamic return to work concept is an expert opinion that is not supported by scientific evidence. However, when return to work is considered to be a dynamic process, achieving full time work is not only an important outcome of successful interventions, but also the maintenance of the work status. This is especially important, because it is likely that there is a risk of recurrent sickness absence after return to work [17]. If this is so, then occupational health monitoring should not end when full return to work is achieved.

Considering the major impact of sickness absence on society, employers, and employees, few studies have reported on the recurrence of sickness absence. $48 \%$ of employees with a long-term episode of sickness absence ( $\geq 6$ consecutive weeks) at baseline had a recurrent longterm episode during a 4-year follow-up, compared to $28 \%$ of employees with no history of long-term sickness absence at baseline [18]. Recurrences of sickness absence have mainly been reported for employees with musculoskeletal disorders, and especially low back pain [19]. In a cohort of 230 Canadian employees who were sick-listed due to low back pain, 29 (12.6\%) had a recurrence of sickness absence due to low back pain within 6 months of return to work [20]. In a population of American employees, Wasiak et al. [21] reported a $17.2 \%$ rate of recurrent work disability due to low back pain within 6 months. Within 12 months, $45 \%$ of employees in The Netherlands experienced a recurrence of sickness absence due to low back pain [22]. Troup et al. [23] reported that 502 out of 802 employees, who had been absent from work due to sciatic back pain, had a recurrence of sickness absence within 24 months.

Using a Markov model to construct a hypothetical cohort of employees, with a follow-up of 40 years, Burdorf and Jansen estimated a total sickness absence burden due to low back pain of approximately 140 weeks (6.6\%) among employees with a high physical load and approximately 30 weeks $(1.4 \%)$ among employees with a low physical load during a 40-year career [24]. However, the Markov model assumes that all information about the future is contained in the present state, meaning that future states are independent of past states. In other words, the Markov model assumes that the probability of transition between health states is constant over time and independent of earlier health states. There is evidence, however, that a history of sickness absence predicts future episodes of sickness absence [25]. Furthermore, it is likely that the risk of sickness absence changes when employees return to work [17].

Instead of using a mathematical Markov model for cohort simulation, studying the incidence and recurrence of sickness absence simultaneously may lead to a better understanding of the natural pattern and distribution of sickness absence in the working population. Therefore, the present study investigated the incidence and recurrence of sickness absence according to diagnosis over a 7-year period. If we can identify categories in which sickness absence is a recurrent problem, then preventive efforts can target to those categories.

\section{Methods}

\section{Dynamic Cohort Study}

This study included employees who worked for the Dutch Post and Telecom in the period from 2001 to 2007. Approximately $70 \%$ of the employees worked for the Dutch Post, mostly as post sorters (repetitive arm movements and lifting post bags), postmen (walking long distances and carrying parcels), or post officers (sedentary clerical work and customer services). The other $30 \%$ of the employees worked for the Dutch Telecom in the installation and maintenance of telephone, telefax, and internet systems or in call center and customer service activities.

The direct measurement of a cumulative incidence traditionally requires a study of a fixed cohort. Such cohorts are suitable as long as the follow-up time and loss to follow-up are limited. However, the turn-over within our study population was high, especially because Dutch Post 
employees work on a temporary basis. This would imply a high loss to follow-up if we chose an inception cohort. Therefore, we preferred a dynamic cohort study design to estimate the incidence density of diagnosis-specific sickness absence. A dynamic cohort is defined as a population that changes because some people enter and others leave during the study period [26]. The advantage of a dynamic cohort is that the population characteristics remain stable, and do not change over time, whereas in an inception cohort, for example, age increases with follow-up.

Employees contributed to the person years at risk as long as they worked for the Dutch Post and Telecom, but their data were right censored on the date on which they left the company, implying that they did not further contribute to the person years at risk, i.e. the denominator of the incidence or recurrence density. Of the 67,316 employees who were included in the study on January 1, 2001, 51,280 resigned or were discharged during the study period. 69,856 employees started working for the Post and Telecom companies after January 1, 2001, and were included on the date that they entered employment; 48,231 of them left their job again before the end of the study period and were right censored on the date on which they left the company.

\section{Sickness Absence Policies}

In The Netherlands, employees report sick to their employer, who passes the sick report onto the occupational health service on the first day of sickness absence. If an employee returns to work within the first two weeks of absence, the employer reports the date of return to work to the occupational health service, and the episode remains self-certified. An employee who does not return to work must visit the occupational physician (OP), usually in the third week of absence, for medical certification of sickness absence according to the 10th International Classification of Diseases [27]. If an employee does not keep an appointment to visit the OP because of full return to work, the sickness absence episode is encoded and registered by an administrator on the date of full return to work with equal earnings as before sickness absence.

\section{Exclusion Criteria}

- Episodes of sickness absence lasting 1-3 weeks, which were not medically certified;

- 2,880 episodes of sickness absence coded by administrators instead of certified by OPs;

- 2,501 episodes of sickness absence certified by OPs as complaints not elsewhere classified (R00-R99, such as fatigue, diffuse pain, and malaise); it is questionable whether these are medical diagnoses and, if so, they are likely to be unreliable;

- 653 episodes of sickness absence certified by OPs as pregnancy and child birth (ICD-10 O00 to O99).

Employees who were absent for longer than 1 year were right censored after 365 days of sickness absence, because a disability pension was granted after 1 year of work disability. Although Dutch disability pension policies changed on January 1, 2004, the recurrence density of medically certified sickness absences did not change abruptly (Fig. 1). The gradual increase in recurrence density up to 2004 and the gradual decrease, thereafter, are due to the time needed for an index episode and a recurrent episode to occur, respectively. Based on these results, we chose to continue to censor employees after 1 year of sickness absence despite the policy changes.

Incidence and Recurrence Density

The first medically certified episode of sickness absence since January 1, 2001, or since the date of entering employment, was regarded as the index episode in this study. It should be acknowledged that this is not necessarily the first episode of sickness absence exceeding 3 consecutive weeks, because people who were employed in January, 2001, may have had earlier episodes of sickness absence. The incidence density (ID) was calculated by dividing incident episodes of sickness absence in each ICD-10 category by the person-years at risk of the total population, and was expressed per 1,000 person-years.

Episodes of certified sickness absence starting more than 28 days after full return to work with equal earnings, were regarded as recurrences. The recurrence density (RD) of sickness absence was calculated by dividing the number of recurrences in an ICD-10 category by the person-years of employees who had a previous episode of sickness absence within the same ICD-10 category. The time to onset of the first recurrence of sickness absence after the

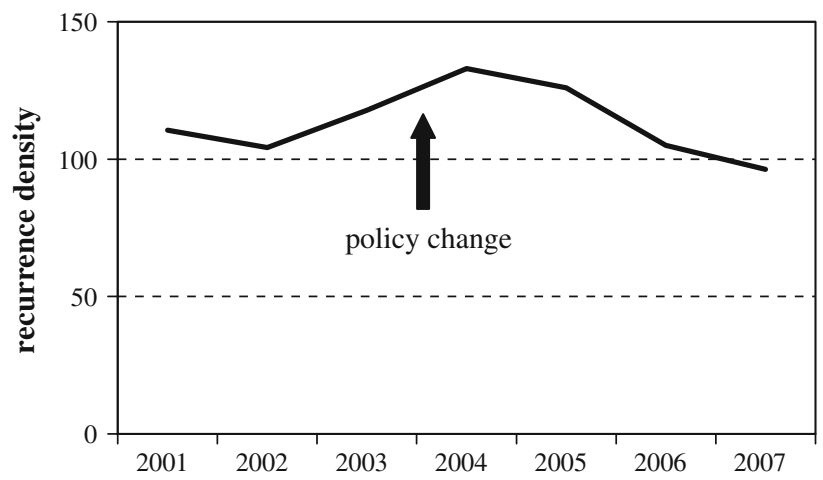

Fig. 1 Trend in the recurrence density per 1,000 person-years during the study period 
index episode and the median duration of recurrent episodes of sickness absence, were calculated with Kaplan-Meier survival analysis. We also counted the total number of days of recurrent sickness absence episodes to assess the burden of recurrent sickness absence per ICD-10 category.

\section{Statistical Analysis of Recurrences}

The following characteristics were retrieved from the human resources registers of the companies: gender (male, female), age ( $<35,35-44,45-54, \geq 55$ years), marital status (married, unmarried), employment (full-time, i.e. $\geq 36 \mathrm{~h}$ per week, or part-time, i.e. $<36 \mathrm{~h}$ per week), the duration of employment (0-4 years, 5-9 years, 10-14 years, 1519 years, $\geq 20$ years), and salary scales $(1-2,3,4-5,6-7, \geq 8$ reflecting net monthly salaries on a full-time basis ranging between EUR 1,200 and EUR 3,000). The salary scales reflected the occupational level rather than the household income. The socioeconomic status (SES) was determined from the zip code of the employee's home address. The zip codes were linked to a status score based on tables of the Netherlands Institute for Social Research, in which all zip codes in the Netherlands are ranked on a scale from 1 to 4,000 , with 1 indicating the richest neighbourhood and 4,000 the poorest neighbourhood. This proxy for SES is commonly used by the Dutch authorities for socioeconomic policy-making $[28,29]$. We computed the quartiles of these status scores, distinguishing between high, upper average, lower average, and low SES.

Gender, age, salary scales, SES, marital status, and employment were included as covariates in a Poisson regression analysis for counts in SPSS version 15 for Windows. The Poisson regression model is expressed as:

$P\left(y=k \mid x_{1}, x_{2}, \ldots x_{i}\right)=e^{-\mu} \mu^{-k} / k ! \quad$ with $k=0,1,2,3 \ldots$

in which the $\log$ of the mean $\mu$ is assumed to be a linear function of the independent variables:

$\log (\mu)=$ intercept $+b_{1} * x_{1}+b_{2} * x_{2}+\cdots+b_{i} * x_{i}$

Considering the huge study population, we chose a $1 \%$ significance level $(\alpha=0.01)$ and computed $99 \%$ confidence intervals (CIs).

\section{Results}

A total of 137,172 employees contributed 363,461 personyears to the study population and 36,342 employees had at least one certified episode of sickness absence between January, 2001 and December, 2007.

The highest IDs were found for sickness absence due to musculoskeletal disorders and mental disorders (Table 1).
The RD of sickness absence due to musculoskeletal disorders was 118.7 per 1,000 person-years, which is 1.5 times higher than the RD in the total population ( 81.6 per 1,000 person-years). The RD of sickness absence due to mental disorders was 80.4 per 1,000 person-years, which is of the same magnitude as the RD in the total population.

The shortest median time to onset of a recurrent episode of sickness absence was found in the category of infectious diseases (Table 2). However, days of sickness absence days due to recurrent infectious diseases accounted for only $1 \%$ of the total number of days of recurrent sickness absence. The median time to onset of a recurrent sickness absence due to musculoskeletal disorders was 409 days after the index episode. Recurrences of sickness absence due to musculoskeletal disorders accounted for $37 \%$ of the total number of days of recurrent sickness absence. The median time to onset of recurrent sickness absence due to mental disorders was 328 days after the index episode, and recurrent episodes of sickness absence due to mental disorders accounted for $21 \%$ of the total number of days of recurrent sickness absence.

Of the 12,129 employees with an episode of sickness absence due to musculoskeletal disorders, 10,678 had complete data, and in 1,451 cases (12\%) data on one or more independent variables were missing. 6,211 of the 7,197 employees with an episode of sickness absence due to mental disorders had complete data, and in 986 cases (14\%) data on one or more independent variables were missing. Poisson regression analysis only included employees with complete data, and showed that employees of upper average and high SES had a lower risk of recurrent episodes of sickness absence due to musculoskeletal disorders compared to employees of low SES (Table 3).

Employees in higher salary scales had a lower risk of recurrent sickness absence due to musculoskeletal and mental disorders than employees in salary scale 1-2 or 3 . Employees who worked for the company for $\geq 5$ years also had a lower risk of recurrences due to musculoskeletal and mental disorders compared to employees who worked for the company for $<5$ years.

\section{Discussion}

This study presents data on the incidence and recurrence of episodes of medically certified sickness exceeding three consecutive weeks of absence from work. The ID and RD of sickness absence due to musculoskeletal disorders were the highest, followed by sickness absence due to mental disorders. Our results showed that recurrences of sickness absence due to musculoskeletal disorders or mental disorders were, in particular, a societal and economic burden, because they accounted for $58 \%$ of the total number of 
Table 1 Incidence density (ID) and recurrence density (RD) of sickness absence (SA) per 1,000 employee-years according to ICD-10 category

\begin{tabular}{llrrrr}
\hline Sickness absence diagnosis & ICD-10 codes & $N$ & ID (99\% CI) & $N$ & RD (99\% CI) \\
\hline Diseases of the musculoskeletal system & M00-M99 & 12,129 & $46.3(45.3-47.2)$ & 4,023 & $118.7(113.8-123.5)$ \\
Mental \& behavioral disorders & F00-F99 & 7,197 & $27.7(27.0-28.4)$ & 1,400 & $80.4(74.9-86.0)$ \\
Diseases of the respiratory system & J00-J99 & 4,568 & $23.3(22.6-24.0)$ & 788 & $74.6(67.8-81.5)$ \\
Injury \& poisoning & S00-T98 & 4,555 & $19.6(19.0-20.2)$ & 480 & $41.9(37.0-46.8)$ \\
Disease of the digestive system & K00-K93 & 1,920 & $10.4(10.0-10.8)$ & 215 & $47.5(39.2-55.9)$ \\
Diseases of the nervous system \& sensory organs & G00-H95 & 1,559 & $8.0(7.6-8.4)$ & 201 & $51.9(42.4-61.3)$ \\
Diseases of the circulatory system & I00-I99 & 1,356 & $6.9(6.5-7.2)$ & 182 & $52.9(42.8-63.0)$ \\
Diseases of the genitourinary system & N00-N99 & 991 & $5.2(4.9-5.5)$ & 95 & $38.8(28.5-49.0)$ \\
Neoplasms & C00-D48 & 618 & $2.8(2.6-3.1)$ & 53 & $42.0(27.1-56.8)$ \\
Infectious \& parasitic diseases & A00-B99 & 566 & $2.5(2.3-2.8)$ & 13 & $9.6(2.7-16.5)$ \\
Diseases of the skin \& subcutaneous tissues & D50-D89 & 501 & $2.7(2.5-3.0)$ & 45 & $35.5(21.8-49.1)$ \\
Endocrine \& metabolic diseases & E00-E90 & 270 & $1.3(1.2-1.5)$ & 43 & $61.2(37.1-85.3)$ \\
Disease of blood \& blood forming organs & L00-L99 & 112 & $0.6(0.5-0.7)$ & 4 & $14.2(0.0-32.5)$ \\
Total & & 36,342 & $101.6(100.2-102.9)$ & 7,542 & $81.6(79.1-84.0)$ \\
\hline
\end{tabular}

CI confidence interval

Table 2 Survival analysis of episodes of recurrent sickness absence

ICD-10 codes $\quad$ Time to onset in days Median duration $\quad$ Total $(\%)$ sickness absence (99\% CI) after index in days (99\% CI) days of all recurrences episode

Diseases of the musculoskeletal system

Mental \& behavioral disorders

Diseases of the respiratory system

Injury \& poisoning

Disease of the digestive system

Diseases of the nervous system \& sensory organs

Diseases of the circulatory system

Diseases of the genitourinary system

Neoplasms

Infectious \& parasitic diseases

Diseases of the skin \& subcutaneous tissues

Endocrine \& metabolic diseases

Disease of blood \& blood forming organs

Total

$\begin{array}{ll}\text { M00-M99 } & 409(386-432) \\ \text { F00-F99 } & 328(284-372) \\ \text { J00-J99 } & 396(353-439) \\ \text { S00-T98 } & 457(375-539) \\ \text { K00-K93 } & 259(148-370) \\ \text { G00-H95 } & 303(205-401) \\ \text { I00-I99 } & 343(179-507) \\ \text { N00-N99 } & 274(187-361) \\ \text { C00-D48 } & 205(92-318) \\ \text { A00-B99 } & 174(18-380) \\ \text { D50-D89 } & 291(230-352) \\ \text { E00-E90 } & 406(176-636) \\ \text { L00-L99 } & 373(11-757) \\ & 384(367-401)\end{array}$

$\begin{array}{cc}36(34-38) & 424,697(37 \%) \\ 62(55-69) & 246,162(21 \%) \\ 11(10-12) & 79,889(7 \%) \\ 35(30-40) & 104,407(9 \%) \\ 28(20-36) & 53,600(5 \%) \\ 21(15-27) & 54,159(5 \%) \\ 65(44-86) & 70,666(6 \%) \\ 39(21-57) & 39,139(4 \%) \\ 215(38-392) & 34,884(3 \%) \\ 34(0-99) & 9,248(1 \%) \\ 18(11-25) & 15,015(1 \%) \\ 40(21-59) & 12,946(1 \%) \\ 50(0-178) & 4,377(0 \%) \\ 35(34-36) & 1,148,187(100 \%)\end{array}$

CI confidence interval

days of recurrent sickness absence. Recurrences of sickness absence due to musculoskeletal disorders and mental disorders were especially frequent in unskilled employees with a short duration of employment.

Musculoskeletal complaints, and particularly low back pain and neck/shoulder/arm pain, are a major health problem in the Netherlands. Our results showed that musculoskeletal disorders were the most common specific cause of sickness absence, and the recurrence of musculoskeletal disorders has been reported to range between 3 and $86 \%$ [30]. The lack of agreement on recurrence rates has been attributed to differences in the definition of a recurrence $[31,32]$ and the heterogeneity of populations in which the rates were calculated. Our results showed that $50 \%$ of the recurrences of sickness absence due to musculoskeletal disorders occurred within 409 days (i.e. approximately $131 / 2$ months) after the index episode. This is in agreement with the findings of Van Duijn and Burdorf, who reported that $45 \%$ of employees in The Netherlands experienced a recurrent sickness absence due to low back pain within 12 months. It should be noted that we studied recurrent sickness absence, which may have resulted in an 
Table 3 Poisson regression analysis of recurrent sickness absence due to musculoskeletal and mental disorders adjusted for company

\begin{tabular}{|c|c|c|c|c|}
\hline & \multicolumn{2}{|c|}{ Musculoskeletal $\left(N^{\mathrm{a}}=10,678\right)$} & \multicolumn{2}{|c|}{ Mental $\left(N^{\mathrm{a}}=6,211\right)$} \\
\hline & $N$ & $\mathrm{RR}^{\mathrm{b}}\left(99 \% \mathrm{CI}^{\mathrm{c}}\right)$ & $N$ & $\mathrm{RR}^{\mathrm{b}}\left(99 \% \mathrm{CI}^{\mathrm{c}}\right)$ \\
\hline \multicolumn{5}{|l|}{ Gender } \\
\hline Male & 6,730 & 1 & 3,477 & 1 \\
\hline Female & 3,948 & $0.98(0.92-1.03)$ & 2,734 & $1.00(0.93-1.09)$ \\
\hline \multicolumn{5}{|l|}{ Age } \\
\hline$<35$ years & 2,023 & 1 & 1,340 & 1 \\
\hline $35-44$ years & 3,492 & $0.97(0.91-1.04)$ & 2,232 & $0.92(0.85-1.01)$ \\
\hline $45-54$ years & 3,794 & $1.00(0.93-1.07)$ & 2,048 & $0.91(0.82-1.00)$ \\
\hline$\geq 55$ years & 1,369 & $1.05(0.96-1.14)$ & 591 & $1.05(0.92-1.20)$ \\
\hline \multicolumn{5}{|l|}{ Marital status } \\
\hline Unmarried & 3,769 & 1 & 2,601 & 1 \\
\hline Married & 6,909 & $0.98(0.94-1.03)$ & 3,610 & $0.95(0.89-1.01)$ \\
\hline \multicolumn{5}{|c|}{ Socioeconomic status } \\
\hline Low & 2,708 & 1 & 1,470 & 1 \\
\hline Lower average & 2,659 & $0.95(0.90-1.01)$ & 1,573 & $1.00(0.92-1.09)$ \\
\hline Upper average & 2,618 & $0.94(0.89-0.99)^{* *}$ & 1,560 & $1.02(0.94-1.11)$ \\
\hline High & 2,693 & $0.93(0.88-0.98)^{* *}$ & 1,608 & $1.01(0.93-1.09)$ \\
\hline \multicolumn{5}{|l|}{ Employment } \\
\hline Full-time & 5,518 & 1 & 3,556 & 1 \\
\hline Part-time & 5,160 & $1.01(0.95-1.07)$ & 2,655 & $1.03(0.94-1.12)$ \\
\hline \multicolumn{5}{|c|}{ Duration of employment } \\
\hline$<5$ years & 3,580 & 1 & 2,014 & 1 \\
\hline $5-9$ years & 1,407 & $0.68(0.63-0.72)^{* *}$ & 758 & $0.72(0.65-0.79)^{* *}$ \\
\hline $10-14$ years & 960 & $0.82(0.75-0.89)^{* *}$ & 773 & $0.81(0.73-0.90)^{* *}$ \\
\hline 15-19 years & 919 & $0.77(0.70-0.84)^{* *}$ & 679 & $0.81(0.73-0.91)^{* *}$ \\
\hline$\geq 20$ years & 3,812 & $0.83(0.77-0.89)^{* *}$ & 1,987 & $0.81(0.74-0.89)^{* *}$ \\
\hline \multicolumn{5}{|l|}{ Salary scale } \\
\hline 1 and 2 & 3,578 & 1 & 1,133 & 1 \\
\hline 3 & 3,980 & $0.96(0.90-1.04)$ & 1,289 & $0.92(0.82-1.03)$ \\
\hline 4 and 5 & 1,302 & $0.87(0.80-0.95)^{* *}$ & 1,063 & $0.88(0.78-0.99)^{*}$ \\
\hline 6 and 7 & 1,221 & $0.79(0.72-0.87)^{* *}$ & 1,497 & $0.87(0.78-0.98) * *$ \\
\hline$\geq 8$ & 597 & $0.66(0.58-0.75)^{* *}$ & 1,229 & $0.82(0.72-0.93)^{* *}$ \\
\hline
\end{tabular}

${ }^{\text {a }}$ Cases with missing values on independent variables are excluded

b $R R$ rate ratio

${ }^{c} C I$ confidence interval with $* P<0.01$ and $* * P<0.001$

underestimation of the recurrence of musculoskeletal pain when employees with complaints continued to work instead of reporting sick.

Recurrences of sickness absence due to musculoskeletal disorders were found to be associated with significant additional suffering, high medical costs, and losses in productivity, contributing disproportionately to the total societal burden of musculoskeletal disease [33-35]. Our results showed that the burden of recurrent sickness absence, in terms of the number of working days lost due to recurrent sickness absence, was highest in the category of musculoskeletal disorders: $37 \%$ of days of recurrent sickness absence were due to musculoskeletal disorders.
Recurrent episodes of sickness absence due to musculoskeletal disorders were related to SES with employees with a low SES being at higher risk than employees of high SES. Health problems and sickness absence are known to occur more frequently among employees with a low SES than in employees of high position [36-40]. Recurrent sickness absence due to mental disorders, however, was not related to the socioeconomic status of employees. Apparently, recurrent sickness absence due to mental disorders is as common in employees with a high SES as in employees of low SES.

The salary scales were associated with the recurrence of sickness absence. Employees with a salary scale ranging 
from 1 to 3 were mostly unskilled postmen and post sorters, or cable workers, whereas, those with a salary scale of 4 and higher were skilled post officers, administrators, computer experts, and managers. Obviously, due to the type of work they do, unskilled employees are at increased risk of recurrent sickness absence due to musculoskeletal disorders.

Besides the type of work, the duration of employment was related to the recurrence of sickness absence. Employees with a short record of service had a higher risk of recurrent sickness absence due to musculoskeletal and mental disorders. On the one hand, employees with a short duration of employment may have difficulties in coping with the work demands. On the other hand, employees who have worked only a few years for a company are likely to be less committed to the company and may find it easier to report sick when having complaints, compared to employees who have worked for $\geq 5$ years for a company.

\section{Policy Implications}

One policy implication of our findings is that the (cost)effectivity of return to work interventions among sicklisted employees with musculoskeletal disorders or mental disorders should not only be estimated according to the duration of the sickness absence episode, but should also be based on recurrent sickness absences after full return to work with equal earnings, especially among unskilled workers with a short record of service. Molde Hagen noticed that, during a 3 year follow-up, there were fewer days of sickness compensation in the intervention group than in the control group [41]. However, this difference was caused by a more rapid return to work during the first year, while there was no significant difference in the second or third year. By performing multi-state analysis, Lie et al. [42] found a short-term effect of an intervention on the transition of the state 'sick-listed' to the state 'returned to work', but no long-term effects on the probability to remain in the latter state. Our results showed that without any intervention, $50 \%$ of recurrent episodes of sickness absence due to musculoskeletal disorders occurred within 409 days after the index episode, and $50 \%$ of recurrent episodes of sickness absence due to mental disorders within 328 days. Thus, the other $50 \%$ of recurrences do not occur in the first year after the index episode. Future intervention studies should not only focus on expediting return to work, but also at sustaining employees at work [43].

Another policy implication of our findings is that, given the considerable burden of recurrent sickness absence, prevention of relapse should be part of any treatment program or intervention aimed at return to work. This implies that employees who have returned to work after a long-term episode of sickness absence are monitored by health care providers to determine whether they are able to sustain the full work status. When complaints increase, or work functioning decreases, employees may consult health care providers who can teach them how to perform activities of daily living, despite their impairments [44], or support them when work adjustments are necessary. Ergonomic worksite assessments, work adjustments, and contacts between health care provider and the workplace reduced the duration of disability and the associated costs $[45,46]$. Although these studies did not focus on recurrences of sickness absence, we assume that workplacebased interventions can be important to sustain employees in their work after a long-term episode of sickness absence. It would be worthwhile to investigate the effects of such interventions as a relapse prevention strategy. Future inception cohort studies are necessary to identify constructs of recurrent sickness absence needed for policy-making. If the results of future clinical trials show that workplacebased interventions also reduce recurrent sickness absence, then they should be targeted at unskilled employees in low occupational classes with a short record of service and low socioeconomic positions, because our results indicate that these employees have the highest risk of recurrent sickness absence.

Strengths and Weaknesses of the Study

The strength of our study is that we could monitor a large dynamic population of employees over a period of 7 years. Furthermore, we used the OP diagnosis on the sickness certificates. However, selecting episodes of sickness absence that are medically certified by OPs implies a source of bias, because sickness absence with a duration of 1-3 weeks is not medically certified, and was not included in the study. Sickness absence was analyzed according to the ICD-10 categories, because the validity of specific diagnoses within the ICD-10 categories has been subject to much debate in occupational health care [47]. The sickness absence register only contained one ICD-10 code per episode, which is a common shortcoming in studies of this type [48]. If an OP changes a diagnosis during an episode of sickness absence, for instance, from a physical disorder to mental disorder, the entire episode is certified as mental disorder. This means that we had no knowledge about co-morbidity. Furthermore, it should be acknowledged that recurrent sickness absence can have different causes, even within the same ICD category. For instance, an employee who was absent from work because of low back pain can have a recurrent episode of sickness absence due to shoulder pain.

Diagnosis-specific recurrences can have been overestimated if OPs are more inclined to certify symptoms and signs in line with earlier diagnoses [48]. The recurrence 
rates may also be biased by return to work. Employees with a serious disease are less likely to return to work, which might explain, for instance, the lower recurrence rates of neoplasms. The risk of recurrence may also have been underestimated because of the high turnover in the study population, since employees who have been absent due to sickness are more likely to resign or to be discharged than employees who have never reported sick [49]. Moreover, the recurrence of sickness absence may depend on social compensation systems. For example, in the Dutch sickness absence insurance system, sickness absences with an interval of less than 28 calendar days, are considered as one episode. However, various different definitions of recurrent episodes have been proposed in research on sickness absence [31, 32]. Therefore, we assume that there are societal differences in the risk of recurrent sickness absence, and recommend that similar research should be carried out in other countries.

Open Access This article is distributed under the terms of the Creative Commons Attribution Noncommercial License which permits any noncommercial use, distribution, and reproduction in any medium, provided the original author(s) and source are credited.

\section{References}

1. Henderson M, Glozier N, Elliot KH. Long term sickness absence. BMJ. 2005;330:802-3

2. Anema JR, van der Beek AJ. Medically certified sickness absence. BMJ. 2008;337:a1174.

3. Kivimäki M, Forma P, Wikstrom J, et al. Sickness absence as a risk marker of future disability pension: the 10-town study. J Epidemiol Community Health. 2004;58:710-1.

4. Kivimäki M, Ferrie JE, Hakberg J, et al. Diagnosis-specific sick leave as a risk marker for disability pension in a Swedish population. J Epidemiol Community Health. 2007;61:915-20.

5. Kivimäki M, Head J, Ferrie JE, Shipley MJ, Vahtera J, Marmot MG. Sickness absence as a global measure for health: evidence from mortality in the Whitehall II prospective cohort study. BMJ. 2003;327:364.

6. Vathera J, Pentti J, Kivimäki M. Sickness absence as a predictor of mortality among male and female employees. J Epidemiol Community Health. 2004;58:321-6.

7. Head J, Ferrie JE, Alexanderson K, Westerlund H, Vahtera J, Kivimäki M. Diagnosis-specific sickness absence as a predictor of mortality: the Whitehall II prospective cohort study. BMJ. 2008;337:a1469.

8. Ferrie JE, Vahtera J, Kivimäki M, et al. Diagnosis-specific sickness absence and all-cause mortality in the GAZEL study. J Epidemiol Community Health. 2009;63:50-5.

9. Whitaker SC. The management of sickness absence. Occup Environ Med. 2001;58:420-4.

10. Gimeno D, Benavides FG, Benach J, Amick BC 3rd. Distribution of sickness absence in the European Union countries. Occup Environ Med. 2004;61:867-9.

11. Gjesdal S, Bratberg E. Diagnosis and duration of sickness absence as predictors for diability pension: results from a threeyear multiregister based and prospective study. Scand J Public Health. 2003;31:246-54.
12. Gjesdal S. From long-term sickness absence to disability pension. Studies on predictors of disability pension in Norway $[\mathrm{PhD}$ thesis]. Bergen (Norway): University of Bergen, 2003.

13. Borg K, Hensing G, Alexanderson K. Risk factors for disability pension over 11 years in a cohort of young persons initially sicklisted with low back, neck, or shoulder diagnoses. Scand J Public Health. 2004;32:272-8.

14. Vaez M, Rylander G, Nygren $\AA$, Åsberg M, Alexanderson K. Sickness absence and disability pension in a cohort of employees initially on long-term sick leave due to psychiatric disorders in Sweden. Soc Psychiatry Psychiatr Epidemiol. 2007; 42:381-8.

15. Høgelund J. Work incapacity and reintegration: a literature review. In: Bloch FS, Prins R, editors. Who returns to work and why? A six country study on work incapacity and reintegration. New Jersey: Transaction Publishers; 2001. p. 27-54.

16. Young AE, Roessler RT, Wasiak R, McPherson KM, van Poppel $\mathrm{MN}$, Anema JR. A developmental conceptualization of return to work. J Occup Rehabil. 2005;15:557-68.

17. Christensen KB, Andersen PK, Smith-Hansen L, Nielsen ML, Kristensen TS. Analyzing sickness absence with statistical models for survival data. Scand J Work Environ Health. 2007;33: 233-9.

18. Koopmans PC, Roelen CAM, Groothoff JW. Risk of future sickness absence in frequent and long-term absentees. Occup Med. 2008;58:268-74.

19. Lötters F, Hogg-Johnson S, Burdorf A. Health status, its perceptions, and effect on return to work and recurrent sick leave. Spine. 2005;30:1086-92.

20. Infante-Rivard C, Lortie M. Relapse and short sickness absence for back pain in the six months after return to work. Occup Environ Med. 1997;54:328-34.

21. Wasiak R, Kim J, Pransky G. Work disability and costs caused by recurrence of low back pain: longer and more costly than in first episodes. Spine. 2006;31:219-25.

22. van Duijn M, Burdorf A. Influence of modified work on recurrence of sick leave due to musculoskeletal complaints. J Rehabil Med. 2008;40:576-81.

23. Troup JD, Martin JW, Lloyd JC. Back pain in industry: a prospective study. Spine. 1981;6:61-9.

24. Burdorf A, Jansen JP. Predicting the long term course of low back pain and its consequences for sickness absence and associated work disability. Occup Environ Med. 2006;63:522-9.

25. Dekkers-Sánchez PM, Hoving JL, Sluiter JK, Frings-Dresen MHW. Factors associated with long-term sick-leave in sick-listed employees: a systematic review. Occup Environ Med. 2008;65: $152-7$.

26. Coggon D, Checkoway H, Pierce NE, Kriebel D, editors. Research methods in occupational epidemiology. Oxford: Oxford University Press; 2004. p. 123-78.

27. World Health Organisation. International classification of diseases and related health problems: ICD-10. Geneva: WHO; 1994.

28. The Netherlands Institute for Social Research http://www.scp. nl/english/.

29. Roes T. Facts and figures of the Netherlands. The Hague: The Netherlands Institute for Social Research; 2007.

30. Oleske DM, Lavender SA, Andersson GBJ, et al. Risk factors for recurrent episodes of work-related low back disorders in an industrial population. Spine. 2006;31:789-98.

31. de Vet HCW, Heijmans MW, Dunn KM, et al. Episodes of low back pain. Spine. 2002;21:2409-16.

32. Hensing G, Alexanderson K, Allebeck P, Bjurulf P. How to measure sickness absence? Literature review and suggestion of five basic measures. Scand J Soc Med. 2004;26:133-44.

33. Watson P, Main C, Waddell G, et al. Medically certified work loss, recurrence and costs of wage compensation for back pain: a 
follow-up study of the working population of Jersey. Br J Rheumatol. 1998;37:82-8.

34. Wasiak R, Pransky G, Verma S, et al. Recurrence of low back pain: definition-sensitivity analysis using administrative data. Spine. 2003;28:2283-91.

35. Abenhaim L, Suissa S, Rossignol M. Risk of recurrence of occupational back pain over 3-year follow-up. Br J Ind Med. 1988;45:829-33.

36. North F, Syme SL, Feeney A, Head J, Shipley M, Marmot MG. Explaining socioeconomic differences in sickness absence: the Whitehall II study. BMJ. 1993;306:361-6.

37. Schrijvers CT, van de Mheen HD, Stronks K, Mackenbach JP. Socioeconomic inequalities in the working population: the contribution of working conditions. Int J Epidemiol. 1998;27: 1011-8.

38. Westert GP, Schellevis FG, De Bakker DH, Groenewegen PP, Bensing JM, van der Zee J. Monitoring health inequalities through general practice: the Second Dutch National Survey of General Practice. Eur J Public Health. 2005;15:59-65.

39. Christensen KB, Labriola M, Lund T, Kivimäki M. Eplaining the social gradient in long-term sickness absence: a prospective study of Danish employees. J Epidemiol Community Health. 2008; 62:181-3.

40. IJzelenberg W, Molenaar D, Burdorf A. Different risk factors for musculoskeletal complaints and musculoskeletal sickness absence. Scand J Work Environ Health. 2004;30:56-63.

41. Molde Hagen E, Grasdal A, Eriksen HR. Does early intervention with a light mobilization program reduce long-term sick-leave for low back pain: a 3-year follow-up study. Spine. 2003;28: 2309-15.
42. Lie SA, Eriksen HR, Ursin H, Molde Hagen E. A multi-state model for sick-leave data applied to a randomized control trial study of low back pain. Scand J Public Health. 2008;36:279-83.

43. Elders LA, van der Beek AJ, Burdorf A. Return to work after sickness absence due to back disorders-a systematic review on intervention strategies. Int Arch Occup Environ Health. 2000;73: 339-48.

44. Swinkels-Meeuwisse IE, Roelofs J, Schouten EG, Verbeek AL, Oostendorp RA, Vlaeyen JW. Fear of movement/(re)injury predicting chronic disabling low back pain: a prospective inception cohort study. Spine. 2006;31:658-64.

45. Franche RL, Cullen K, Clarke J, Ivrin E, Sinclair S, Frank J. Workplace-based return to work interventions: a systematic review of the quantitative literature. J Occup Rehabil. 2005;15: 607-31.

46. Steenstra IA, Knol D, Bongers PM, Anema JR, van Mechelen W, de Vet HC. What works best for whom? An exploratory subgroup analysis in a randomized controlled trial on the effectiveness of a workplace intervention in low back pain patients on return to work. Spine. 2009;34:1243-9.

47. Hensing G, Wahlström R. Sickness absence and psychiatric disorders. Scand J Public Health. 2004;32(Suppl 63):152-80.

48. Wahlström R, Alexanderson K. Physician's sick-listing practices. Scand J Public Health. 2004;32(suppl 63):222-55.

49. Koopmans PC, Roelen CAM, Groothoff JW. Frequent and longterm sickness absence as a risk factor for work disability and job termination among employees in the private sector. Occup Environ Med. 2008;65:494-9. 